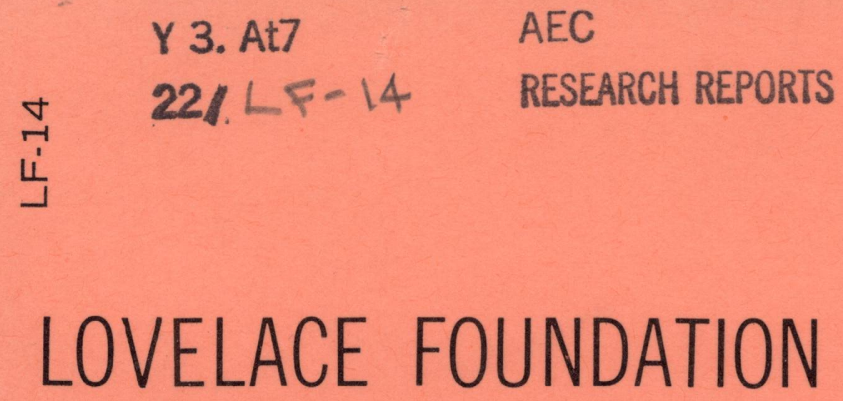

for Medical Education and Research

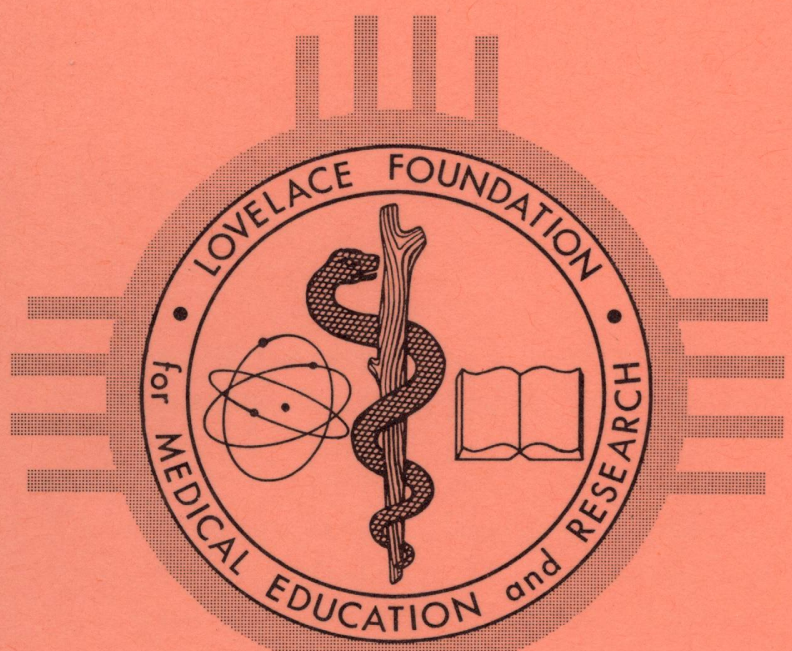

Albuquerque, New Mexico
AEC RESEARCH AND DEVELOPMENT REPORT

UNCLASSIFIED

UNIVERSITY OF ARIZONA LIBRARY Documents Collection SEP 161964

\section{A GAMMA RAY DETECTOR OF VARIABLE GEOMETRY FOR WHOLE BODY COUNTING OF SMALL ANIMALS.}

July, 1964

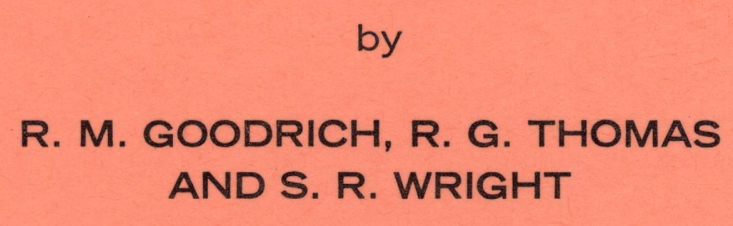

by

R. M. GOODRICH, R. G. THOMAS 


\section{LEGAL NOTICE}

This report was prepared as an account of Government sponsored work. Neither the United States, nor the Commission, nor any person acting on behalf of the Commission:

A. Makes any warranty or representation, express, or implied, with respect to the accuracy, completeness, or usefulness of the information contained in this report, or that the use of any information, apparatus, method, or process disclosed in this report may not infringe privately owned rights; or

B. Assumes any liabilities with respect to the use of, or for damages resulting from the use of any information, apparatus method, or process disclosed in this report.

As used in the above, "person acting on behalf of the Commission" includes any employee or contractor of the Commis sion to the extent that such employee or contractor prepares, handles or distributes, or provides access to, any information pursuant to his employment or contract with the Commission.

Printed in USA. Price $\$ 0.50$. Available from the Office of Technical Services, Department of Commerce, Washington 25, D. C. 
LF - 14

Biology \& Medicine

UNCLASSIFIED

and

Instruments

TID-4500 (31 st Ed.)

\begin{abstract}
A GAMMA RAY DETECTOR OF VARIABLE GEOMETRY FOR WHOLE BODY COUNTING OF SMALL ANIMALS.
\end{abstract}

by

R. M. Goodrich, R. G. Thomas and S. R. Wright

Submitted as a

Technical Progress Report

to

The Division of Biology and Medicine

United States Atomic Energy Commission

on

Contract No, AT(29-2)-1013

July, 1964

From the Departments of Aerosol Physics and Radiobiology

Lovelace Foundation for Medical Education and Research

Albuquerque, New Mexico

UNCLASSIFIED 
do 


\begin{abstract}
ABST RACT
A gamma ray detector for counting small animals in metabolism cages has been constructed. The cage is centered between horizontal coaxial NaI crystals. By varying the distance of separation between the crystals the counting efficiency of the detector for $I^{131}$ can be varied from approximately $6 \%$ to $0.24 \%$, making it possible to count a wide range of source activities. The detector is shielded by four inches of lead which allows for considerable stability in background counting rates. Various aspects of the counter performance have been studied and are presented in graphical form with some discussion of the characteristics. These include determinations of efficiency as a function of crystal separation, gamma ray energy and point versus bulk source. A short treatment of the effect of scattering is also included.
\end{abstract}


i 


\section{TABLE OF CONTENTS}

Page

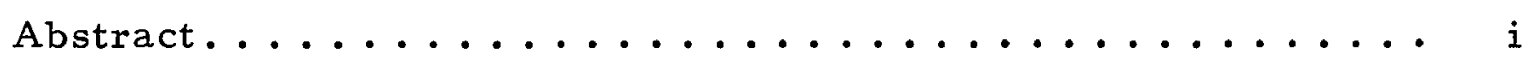

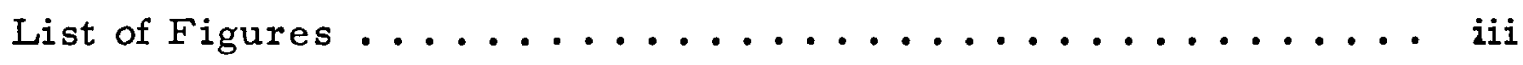

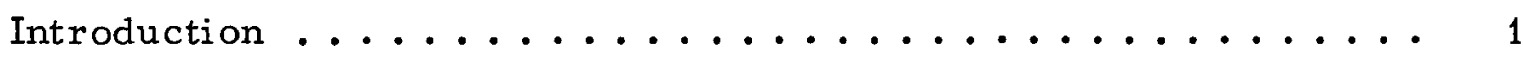

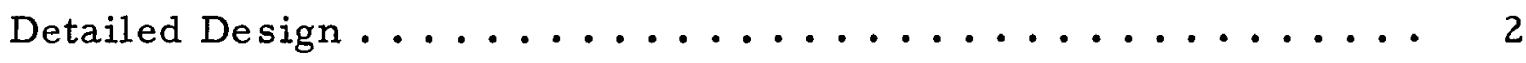

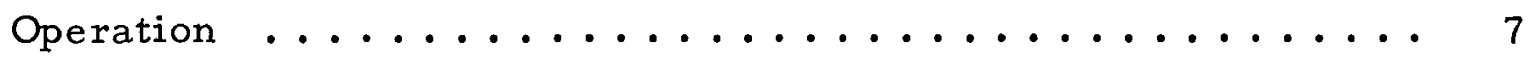

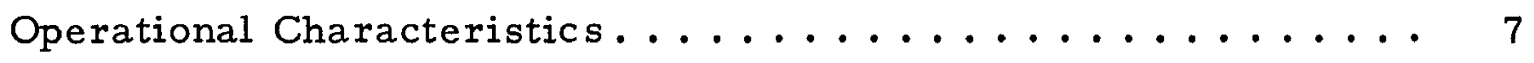

Background Stability..................... 14

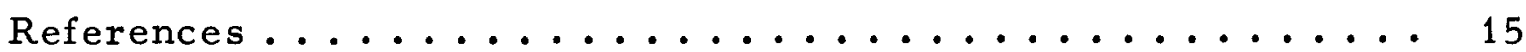




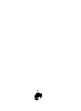




\section{LIST OF EIGURES}

Figure

1. System Partially Dismantled Showing Crystal

Dollies and Cage in Position for Counting. ........ 3

2. Detail Drawing of Counter Drive Assembly. . . . . . . 4

3. System Partially Dismantled Showing Door and

Top Supports in Place. ................. 5

4. Completely Assembled Counter With Cover and

Top Supports in Place. ................. 6

5. Rats in Cage Positioned for Counting. .......... 8

6. Efficiency of System in $\frac{\mathrm{cpm}}{\mathrm{Y}^{1} \mathrm{~s} / \mathrm{min} \text {. }}$ for Four

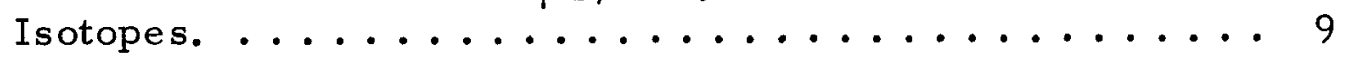

7. Effect of Scattering for Integral Counting With

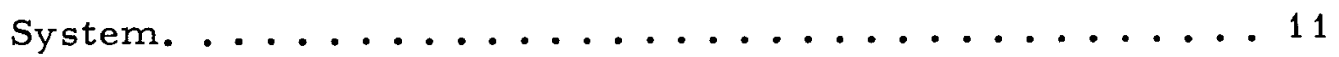

8. Effect of Coincidence Losses on Count Rate

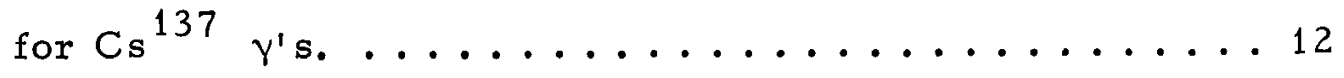

9. Effect of Lateral Movement in Counting Chamber...... 13 



\title{
A GAMMA RAY DETECTOR OF VARIABLE GEOMETRY FOR WHOLE BODY COUNTING OF SMALL ANIMALS.
}

\author{
by \\ R. M. Goodrich, R. G. Thomas and S. R. Wright \\ INTRODUCTION
}

In our studies of the biological effects of inhaled mixed fission products, most experimental animals are housed in metabolism cages following exposure to the aerosol. A metabolism cage, designed for efficient separation of urine and feces, normally contains one guinea pig, two rats or five mice. Daily or periodic excreta collections are made and the quantity of fission product(s) present in each fraction is determined by radioactivity measurement. It is desirable to obtain periodic whole body counts on these animals to correlate with body burdens estimated from excretion data. With this type of study it is imperative that no loss of, of cross-contamination between, urine and feces occurs during the whole body counting. It is desirable, therefore, to count the animals in their respective metabolism units. ${ }^{1}$

A gamma ray detection system has been designed and employed which is of suitable sensitivity and of sufficient size that the entire metabolism cage, with animals inside, may be placed into the counting chamber for a whole body radioactivity determination. Thallium activated sodium iodide crystals were selected as detectors because of the requirement to separate closely spaced gamma ray photo peaks. It is the opinion of the authors that a detection system of this type might find wide usage, not only for small animal counting but for any application in which samples vary widely in their radioactive content.

This report describes the construction and performance of such a counting system. 


\section{DETAILED DESIGN}

The system employs two $5^{\prime \prime}$ diameter $\times 3^{\prime \prime}$ sodium iodide crystal detectors mounted horizontally facing each other (see Figure 1).

The crystals with their associated photomultipliers and battery high-voltage supplies are mounted on dollies and driven by a coupled shaft with opposing threads. The counter base plate and drive shaft are shown in Figure 2. The 36" of travel over the threaded sections allows for the crystals to be moved from their closest position of 30 centimeters face-to-face to the maximum extended position of 2 meters face-to-face. The motor is geared to $120 \mathrm{rpm}$ and drives the crystals with a belt coupling. The combination of $120 \mathrm{rpm}$ and 10 threads per inch on the shaft provide the dolly speed of $12^{\prime \prime}$ per minute. This is sufficient to position the crystals in a relatively short time without significant "coasting" of the motor after power is removed. Mounted on the aluminum sheet are six micro switches which are connected to a panel of lights to indicate the position of the crystals within the counter. It was arbitrarily decided to count at six face-to-face distances, namely $30,50,70,100,150$ and 200 centimeters. This range of separation is very adequate for the counting operations involved.

The counting chamber is shielded on all sides by four inches of lead (approximately 600 milled lead bricks). The top of the counter is laid in three sections to allow maintenance on either crystal or the central chamber without dismantling the entire shield (see Figure 3). Only the front need be removed to service the crystal as sembly. The shaft which supports the door is welded to the center table section; the weight of the door is supported by a thrust bearing and the door is guided by needleroller bearings. The door requires only one hand for operation, even by female technicians.

The assembled detector is covered by a sectional sheet metal cover with a baked enamel finish and appears as below in Figure 4. The overall dimensions are approximately $3.2 \mathrm{ft}$. high, $2 \mathrm{ft}$. deep and $12.2 \mathrm{ft}$. long. 


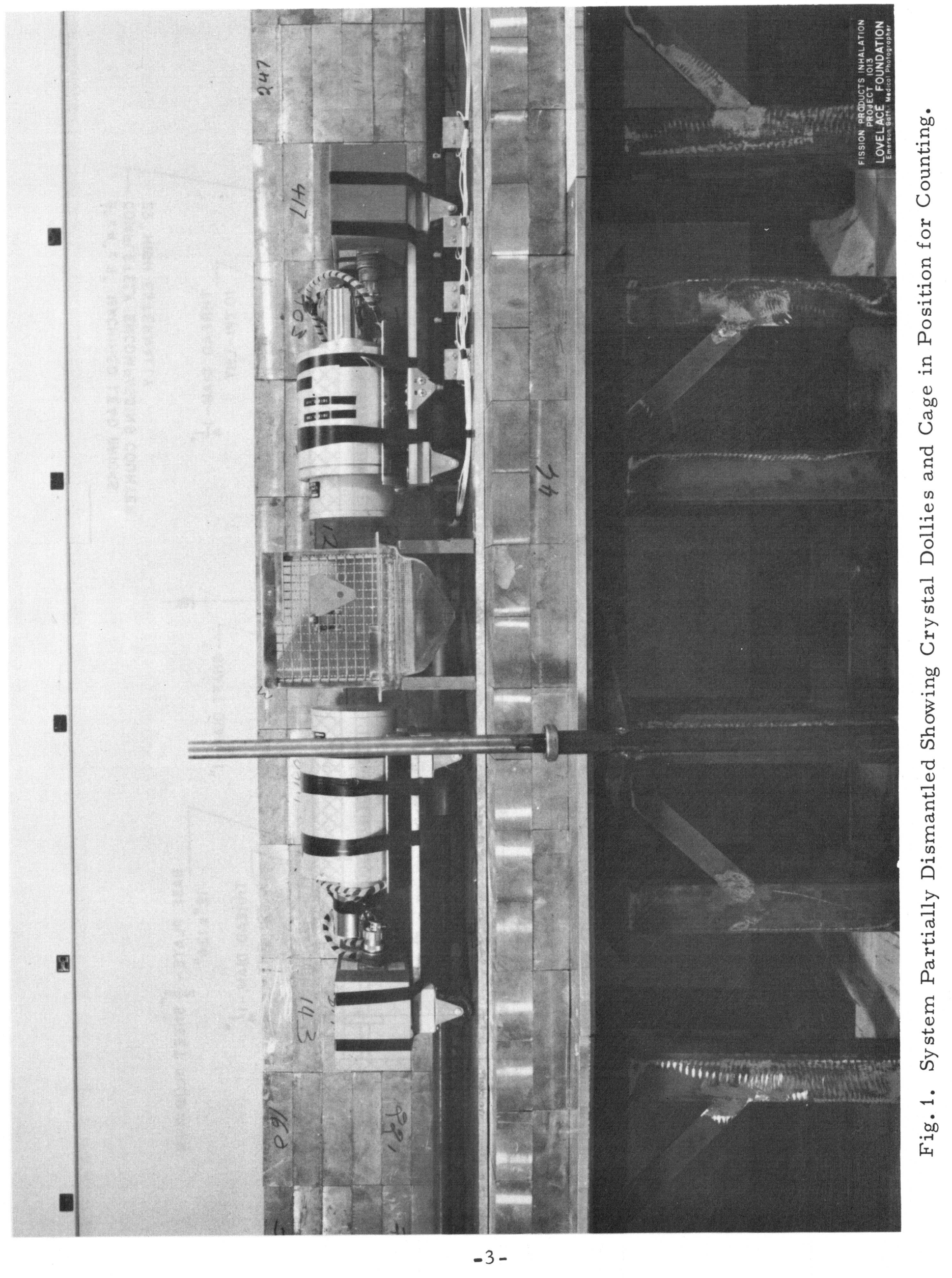




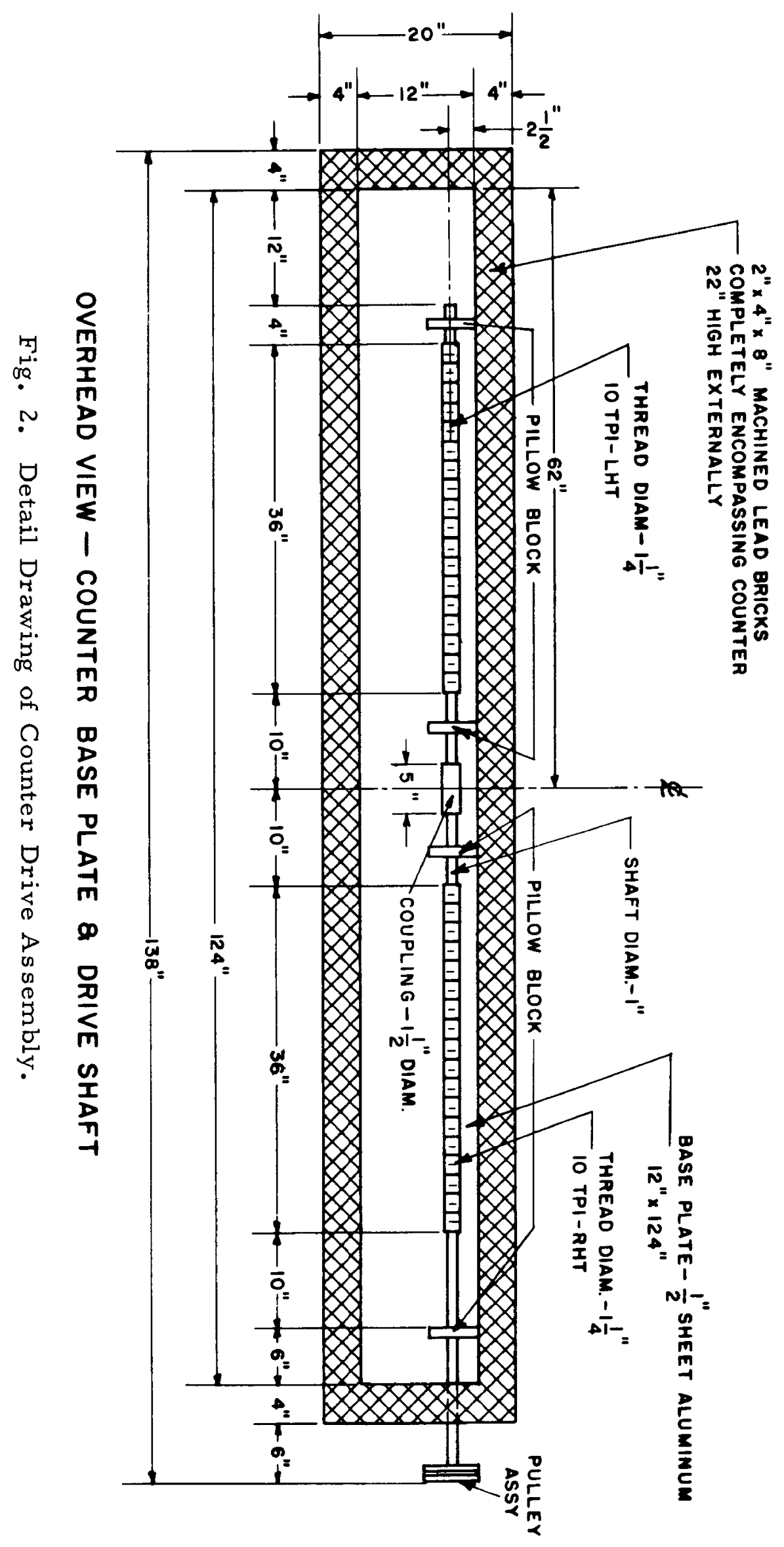




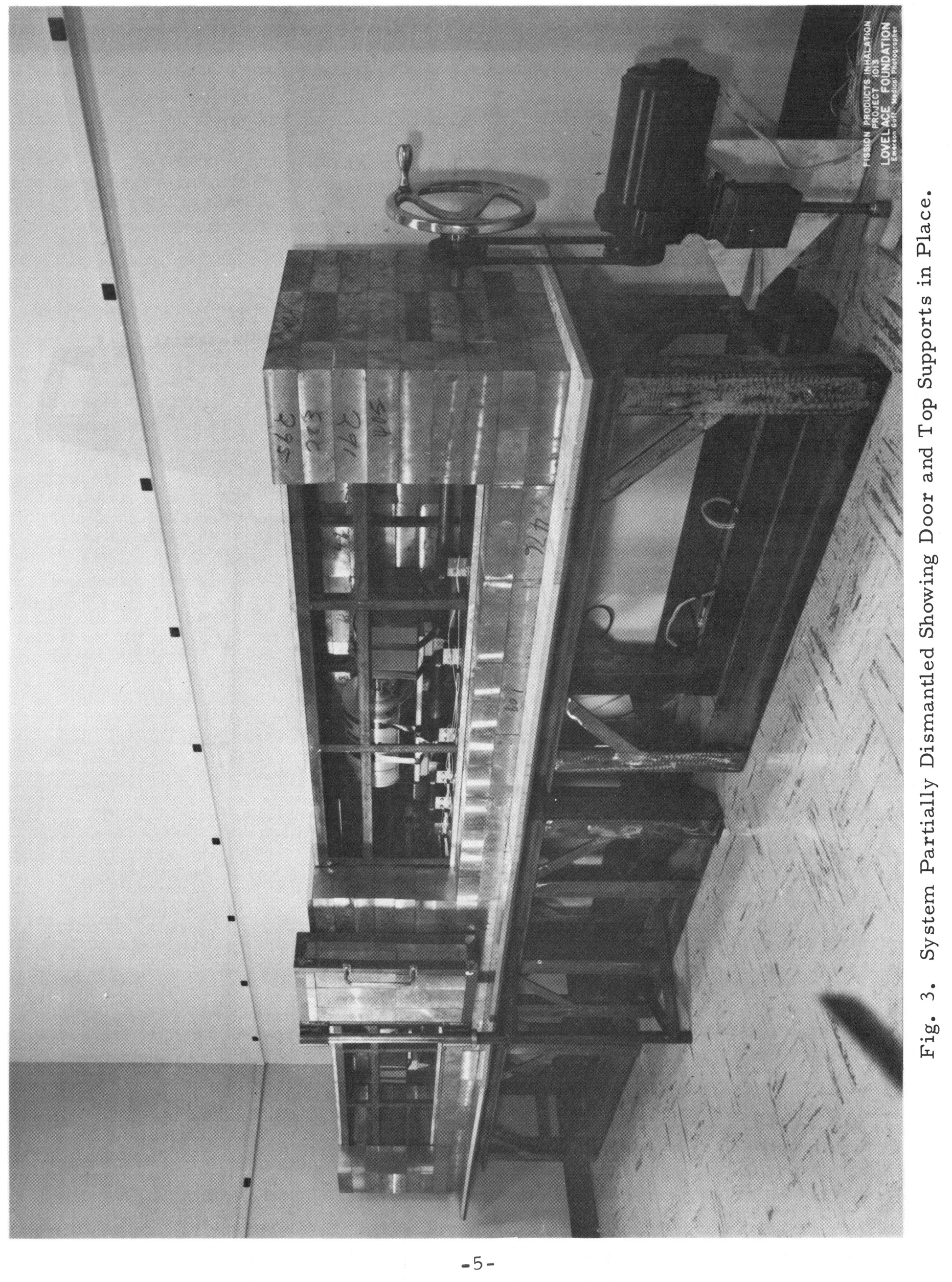




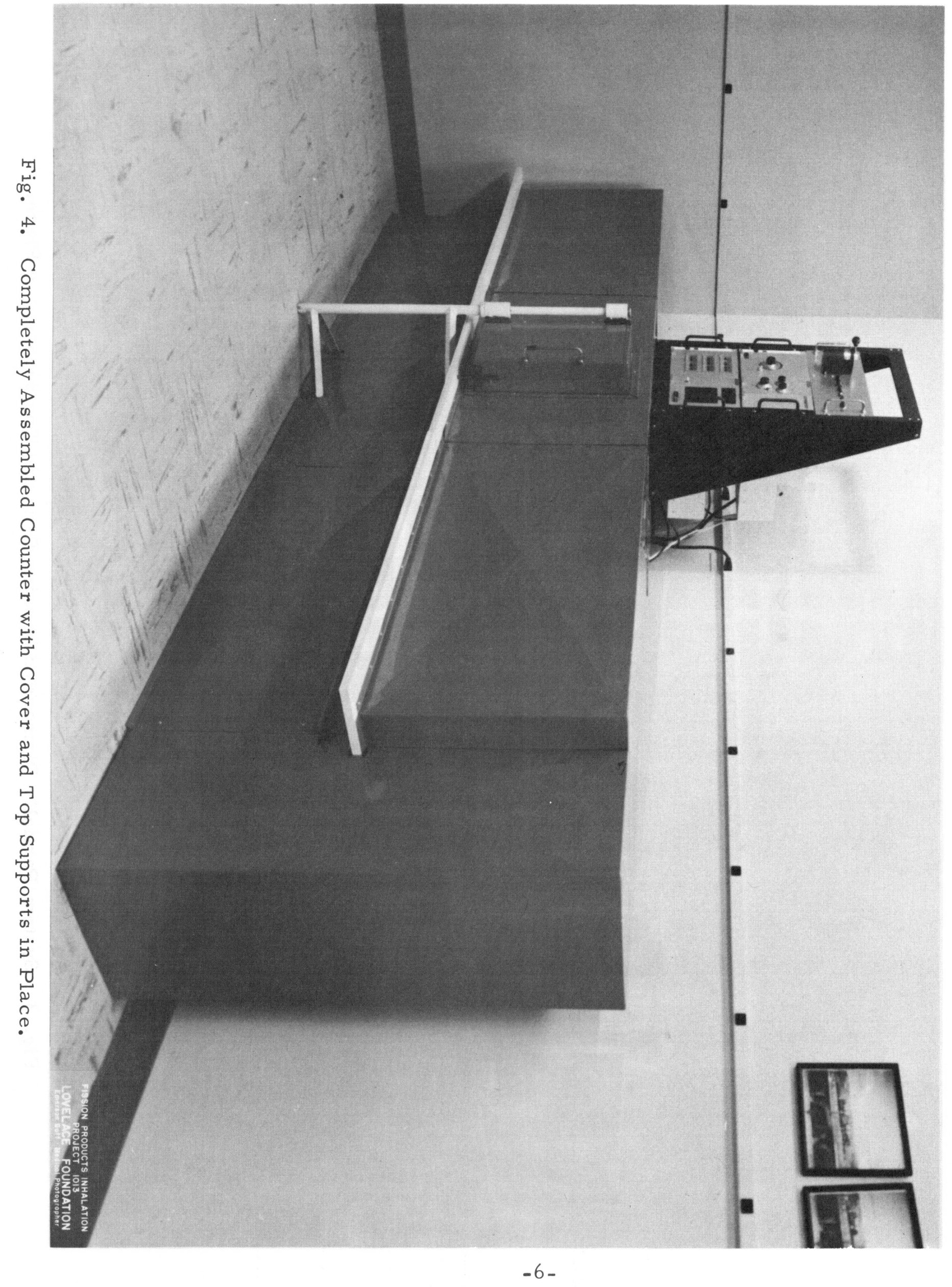




\section{OPERATION}

After animals have been transferred to a clean metabolism cage the entire cage unit is inserted into the counting chamber. ${ }^{1}$ A plexiglass restrainer is inserted in the cage to restrict the animal motion to near the center-line of the crystals (see Figure 5). Minimum sensitivity in geometry is obtained when the crystal separation is greatest. The animals are therefore counted at the maximum separation which will yield acceptable statistical values. Generally, when the animals reach radioactive body burdens that are a factor of two times the background the crystals are moved to the next closer position. To obtain maximum utilization of the counter, it is preferable to move the crystals closer to the animals to obtain acceptable data as opposed to increasing the counting time.

When the radioactive material in an animal has decreased (either due to biological or physical processes) to such an extent that they no longer yield statistically significant whole body counts, their excreta most certainly contains so little radioactivity that they can be removed from metabolism cages. Subsequently they may be placed in ordinary cages and counted periodically in a much more sensitive well detector to follow the long term components of the fission product retention.

\section{OPERATIONAL CHARACTERISTICS}

The detectors* employ Dumont 6364 Photomultipliers and are operated from battery high-voltage supplies providing 1050 volts. Under these conditions, the efficiency for $\mathrm{I}^{131}$ varies from a high of $6 \%$ to a low of $0.24 \%$ over the range of crystal separation. Efficiency as a function of crystal separation is shown in Figure 6 for four isotopes; $\mathrm{Sr}^{85}, \mathrm{Cs}^{137}, \mathrm{I}^{131}$, and $\mathrm{Co}^{60}$. At the shorter separation distances, the

* Harshaw Chemical Co., Cleveland 6, Ohio 


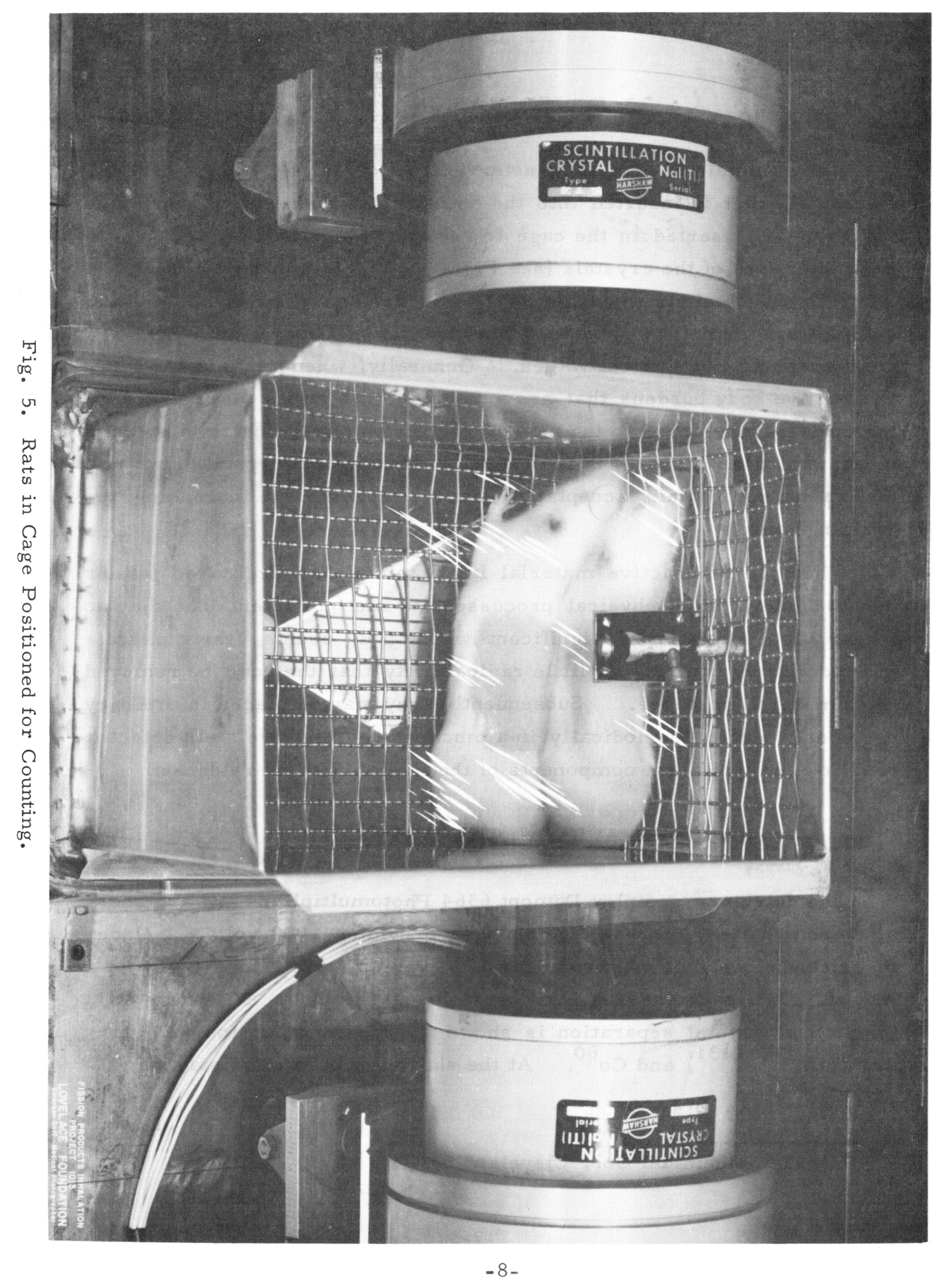




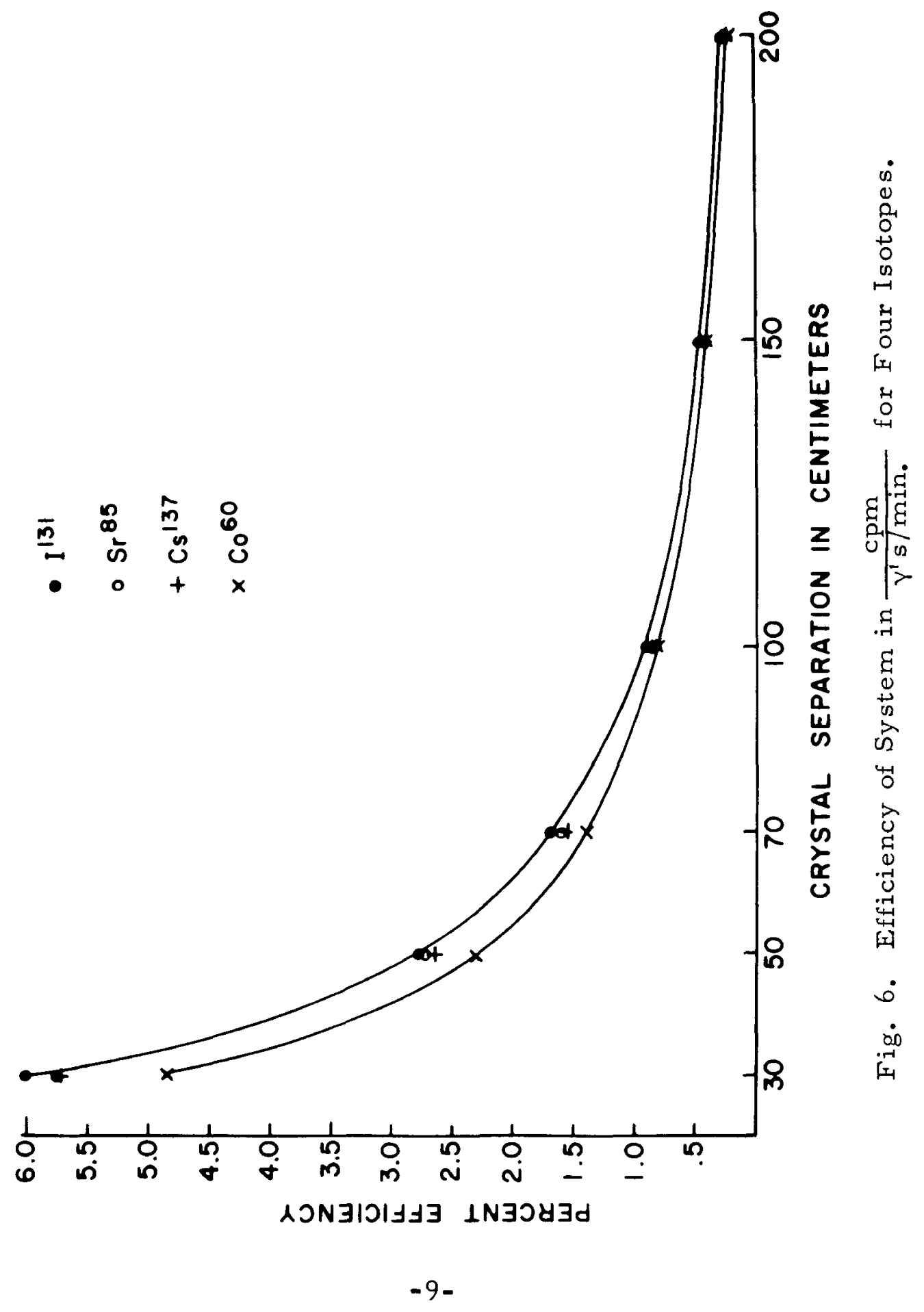


efficiency is lower for the more energetic gammas for which the absorption coefficients in NaI are lower. With increasing separation distance, the relatively greater amount of scattering produced by the higher energy gamma radiation narrows the difference between the efficiency curves.

The scattering effect is demonstrated in Figure 7, where relative efficiency as percent of the $30 \mathrm{~cm}$ value is plotted as a function of separation of crystal faces for $\mathrm{Ba}^{133}, \mathrm{Cs}^{137}$, and $\mathrm{Co}^{60}$. The theoretical response (practically all due to inverse square relationships) for $\mathrm{Cs}^{137}$ is drawn on the graph. The actual response of the counter to $\mathrm{Cs}^{137}$ is indicated by the plotted points. The increasing separation of the empirical points from the theoretical line with increased crystal separation is an indication of the scattering within the counter. The scattering effect increases with crystal separation distance and with gamma ray energy. It should be possible to minimize this scattering effect by using a single-channel analyzer and differential counting techniques.

Figure 8 depicts net counts per minute versus disintegrations per minute for $\mathrm{Cs}^{137}$ counted at the fixed crystal settings. The straight-line portion of the curves has a slope of one on the $\log -\log$ plot which indicates a linear function. The reduced slope at the shorter separation distances with high count rate is an indication of the coincidence loss in the two crystals. This demonstrates that approximately a millicurie of $\mathrm{Cs}^{137}$ can be counted at the longer separation distances with little or no coincidence loss.

Figure 9 shows the effect of lateral movement of both point and bulk sources within the counting chamber. Per cent of count rate increase as the source is moved from the mid-point (between crystal faces) is plotted as a function of distance from the center. Variation in count rate of a point source of $\mathrm{Sr}^{85}$ of approximately $0.4 \mu \mathrm{c}$ is plotted in 9-a for all fixed crystal separations. The counter is a great deal more sensitive to movement at the shorter separation distances as would be expected. For this reason, it is desirable to count with the separation as greatas practical. Figure 9-b illustrates the effect of lateral movement of a $\mathrm{Sr}^{85}$ 
Fig. 7. Effect of Scattering for Integral Counting with System.

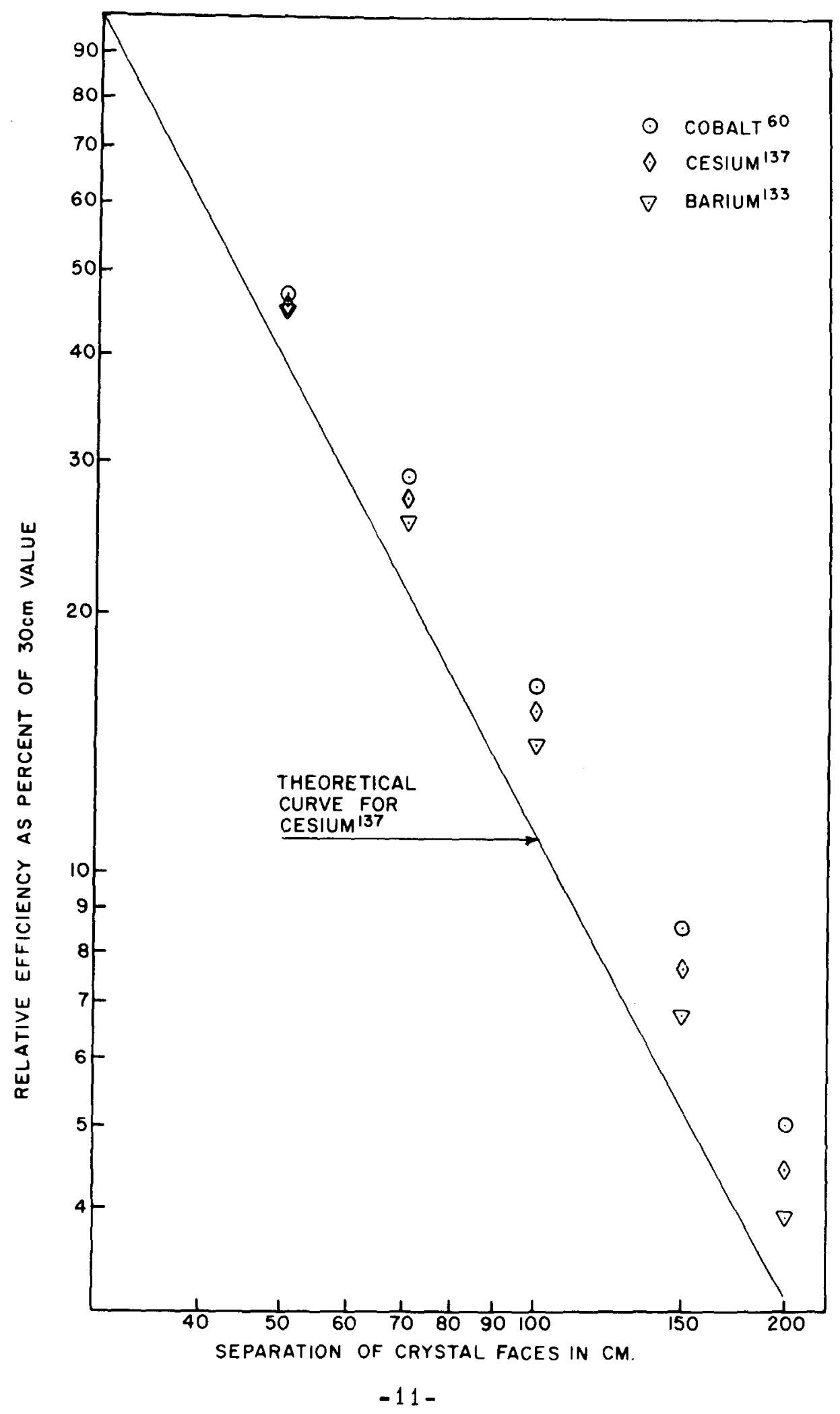




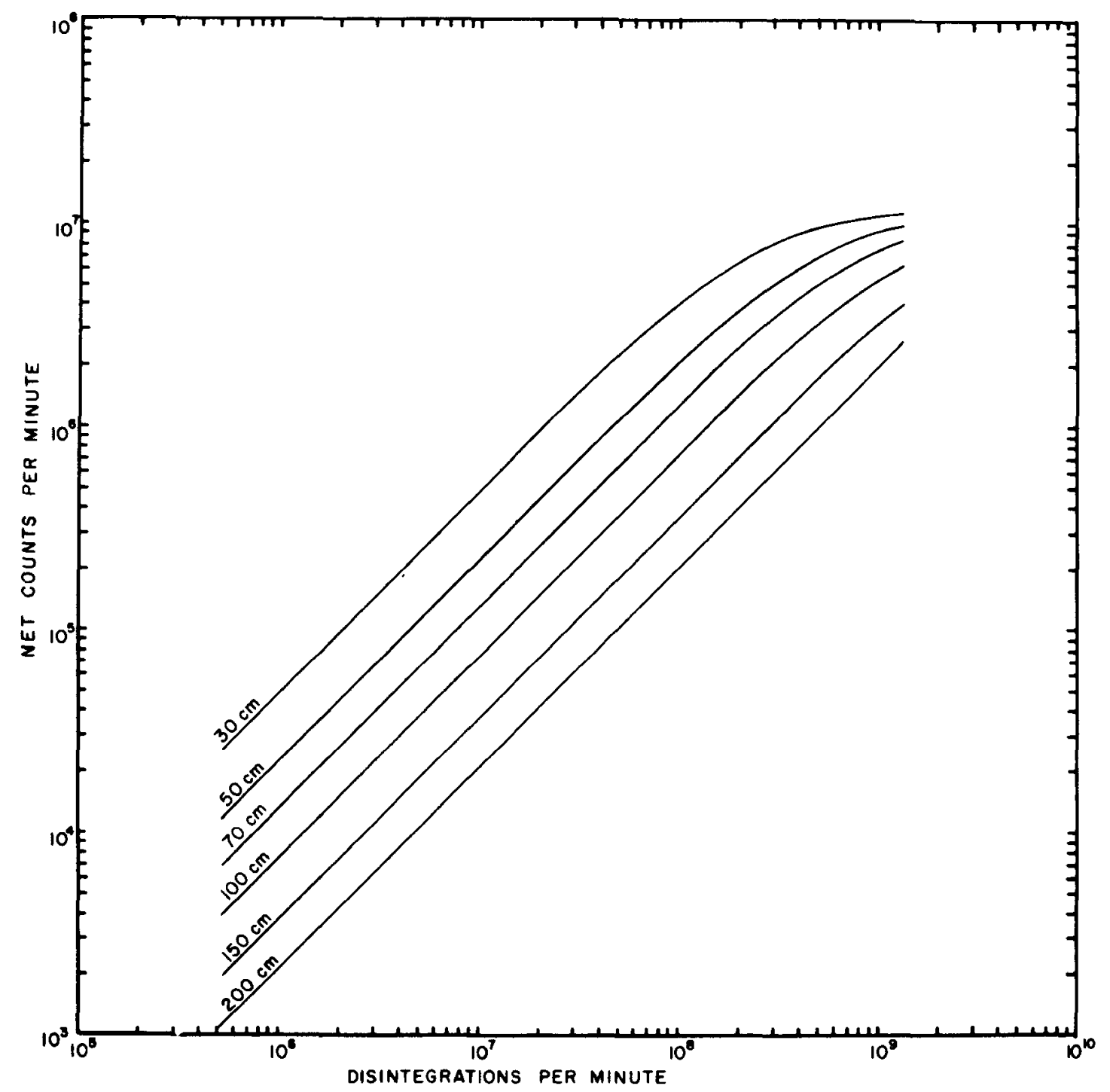

Fig. 8. Effect of Coincidence Losses on Count Rate for Cs ${ }^{137} \gamma^{\prime} s$. 

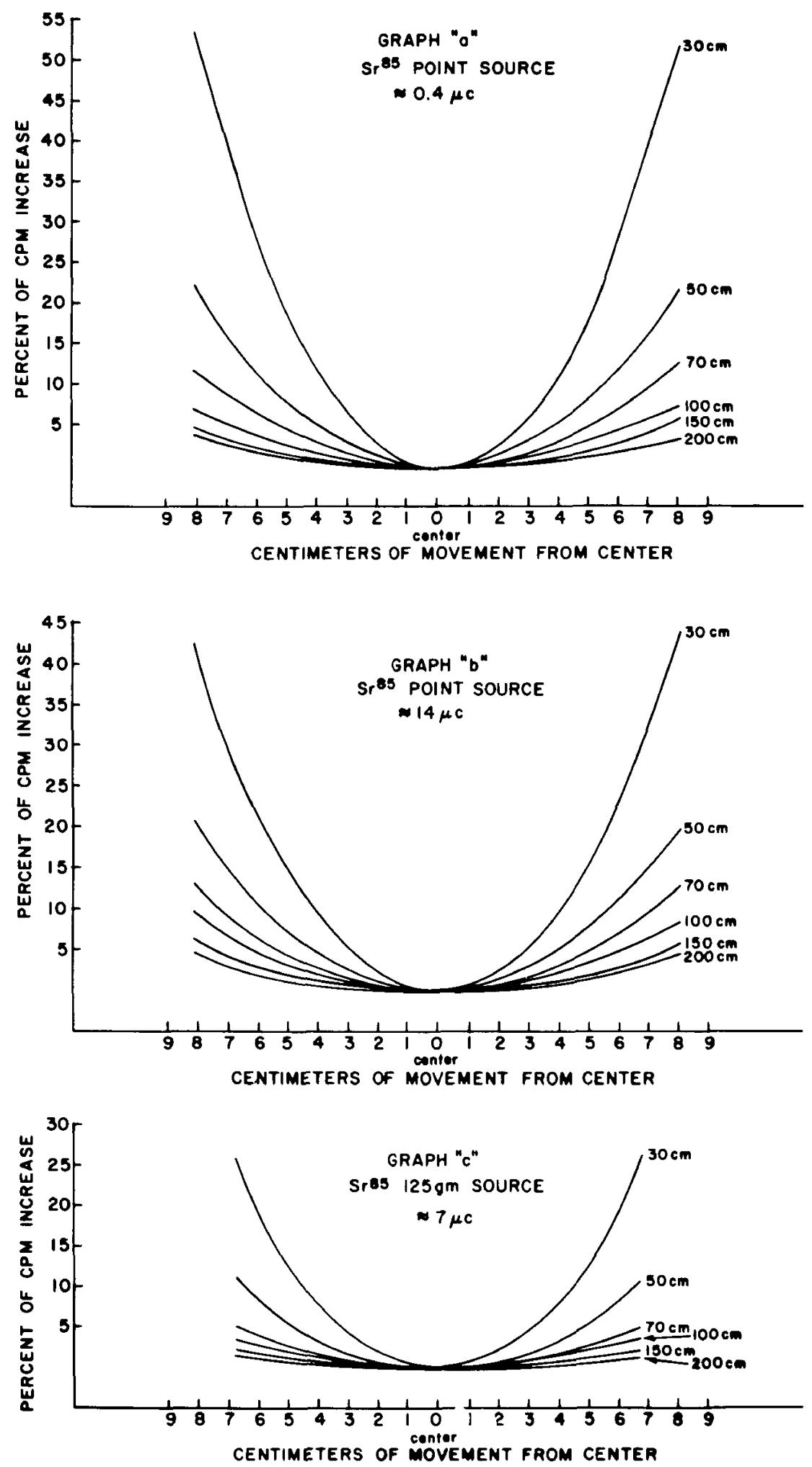

Fig. 9. Effect of Lateral Movement in Counting Chamber. 
point source of approximately $14 \mu \mathrm{c}$. The change with movement is somewhat hidden by coincidence losses at the shorter separation distances but with proper corrections for high counting rate losses, this figure is the same as 9-a. Figure 9-c is a much better representation of the movement of an animal or large source as compared to a point source. Changes in count rate are not so great with lateral movement for the 125 gm source.

These effects pose some limitation on the use of the counter since if it is necessary to count animals capable of much lateral movement at short crystal separation distances they must be restricted to the center of the cage.

\section{BACKGROUND STABILITY}

To assess the counter stability, 49 background counts spanning a time period of 7 days were subjected to statistical analysis. These were obtained in five minute counting intervals and had a mean of 3258 net counts per minute with a range of 3125 to 3359. Six 50 counts per minute intervals which span this range were chosen and the frequency of occurrence of backgrounds in each interval was determined. A chi square "goodness of fit" test was performed to see if the data followed a normal distribution. The calculated $x^{2}$ was 2.61 compared to the theoretical value of 9.49 , for this number of degrees of freedom at the $95 \%$ confidence level. This is a strong indication that the background counts are normally distributed; with the large number of values involved they also are fitted by a Poisson distribution. The standard deviation for all of the counts was 54.8 counts per minute or $1.7 \%$ of the mean. 
$\underline{\text { REFERENCES }}$

1. Thomas, R. G. and R. Lie: Procedures and Equipment Used in Inhalation Studies on Small Animals. Lovelace Foundation, Report LF-11, 1963. 


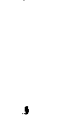



